\title{
Contrasting the crospovidones functionality as excipients for direct compression
}

\author{
Daniel García Ramírez, Leopoldo Villafuerte Robles*
}

Pharmacy Department, National School of Biological Sciences, National Polytechnic Institute of Mexico

\begin{abstract}
Specific values of technological properties of excipients allow the establishment of numerical parameters to define and compare their functionality. This study investigates the functionality of Polyplasdones XL and XL10. Parameters studied included tablet disintegration profiles, compactibility profiles and powder flow. The results allowed the establishment of quantitative surrogate functionalities of technological performance, such as absolute number, and as a value relative to the known microcrystalline cellulose type 102. Moreover, the establishment of an explicit functionality to improve the technological performance of two diluents and a model drug was investigated, as was setting up of these functionalities, as quantitative values, to determine the input variables of each material and its probable functionality in a drug product. Disintegration times of pure Polyplasdone XL and its admixtures were around half that of Polyplasdone XL10. The improvement in tablet compactibility was $25-50 \%$ greater for Polyplasdone XL10 than Polyplasdone XL. Crospovidones proportions of up to $10 \%$ have little effect on the flow properties of other powders, although pure Polyplasdone XL10 and its admixtures display compressibility indexes about 20\% greater than Polyplasdone XL. The observed results are in line with a smaller particle size of Polyplasdone XL10 compared to Polyplasdone XL.
\end{abstract}

Uniterms: Excipients/functionality. Polyplasdones XL/functionality. Polyplasdones XL10/functionality. Tablets/compactibility. Tablets/disintegration time. Tablets/powder flow. Amoxicillin. Magnesium stearate. Superdisintegrants.

Os valores específicos de propriedades tecnológicas de excipientes permitem o estabelecimento de parâmetros numéricos para definir e comparar a sua funcionalidade. Este estudo investiga a funcionalidade dos excipientes. Os parâmetros estudados foram perfis de desintegração dos comprimidos, perfis de compactação e fluxo de pó. Os resultados permitiram expressar o desempenho tecnológico através de valores absolutos e valores relativos à conhecida celulose microcristalina tipo 102. Do mesmo modo, permitiram estabelecer uma funcionalidade explícita para melhorar o desempenho tecnológico de dois diluentes e um fármaco modelo. A criação destas funcionalidades, como valores quantitativos, permite conhecer as variáveis de entrada de cada material e sua provável funcionalidade em um medicamento. Os tempos de desintegração do Poliplasdone XL e das suas misturas são cerca da metade do observado para as misturas com o Poliplasdone XL10. Melhoria da compressão de comprimidos que contêm Polyplasdone XL10 é 25-50\% maior do que o Polyplasdone XL. Crospovidonas em proporções de até $10 \%$ têm pouco efeito sobre as propriedades de fluxo dos outros pós embora o Poliplasdone XL10 e suas misturas exibam índices de compressibilidade cerca de $20 \%$ maior do que o Poliplasdone XL. Os resultados observados estão em sintonia com o menor tamanho de partícula do Poliplasdone XL10, em comparação com o Poliplasdone XL.

Unitermos: Excipientes/funcionalidade. Poliplasdones XL/funcionalidade. Poliplasdones XL10/ funcionalidade. Comprimidos/perfil de compactibilidade. Comprimidos/tempo de desintegração. Comprimidos/fluxo de pó. Amoxicilina. Estearato de magnésio. Superdesintegrantes.

\footnotetext{
*Correspondence: L. Villafuerte Robles. Departamento de Farmacia, Escuela Nacional de Ciencias Biológicas, Instituto Politécnico Nacional de México. Av. Wilfrido Massieu s/n esq. M. Stampa, Unidad Profesional Adolfo López Mateos, Col. Industrial Vallejo, C. P. 07738, D. F., México. E-mail: 1villaro@encb.ipn.mx; 1villarolvillaro@hotmail.com
} 


\section{INTRODUCTION}

Cross-linked polyvinylpyrrolidones or crospovidones are synthetic, insoluble, cross-linked homopolymers containing less than $1.5 \%$ of soluble material. Crospovidone particles are granular, highly porous and do not form complexes with drugs. These disintegrants accelerate tablet disintegration by the absorption of great quantities of water when exposed to aqueous media. Variation of the medium $\mathrm{pH}$ does not affect the disintegrant action of crospovidones. Crospovidones are used at low concentration levels (2-5\%) in direct compression, for wet and dry granulation processes (Kumar, Nirmala, 2012; Chen et al., 1997).

In contact with water, crospovidone readily forms a hydration layer around the particles, gradually filling and saturating their internal pores. The cross-linked structure of crospovidone behaves as a mesh to prevent the loss of water trapped within the internal pores; its mechanism of action resembles the sponge model proposed for microcrystalline cellulose (Jain et al., 2010).

Crospovidone is one of the three superdisintegrants described in the literature. Crospovidone is a disintegrating agent at the $2-5 \%$ level and is effective in tablets prepared using wet granulation. It is considered that its swelling properties paired with particle-size distribution enable the finer grades of crospovidone to work efficiently in fast-disintegrating formulations (Quadir, Kolter, 2006).

Crospovidone is available in several grades differing mainly in the particle size, for example Polyplasdone XL is a coarser grade while Polyplasdone XL10 is a finer grade. The smaller particle size of polyplasdone XL10 $(25-40 \mu \mathrm{m})$ generates bulk and tapped densities of $0.3 \mathrm{~g} / \mathrm{mL}$ and $0.5 \mathrm{~g} / \mathrm{mL}$, respectively, while Polyplasdone XL, with a particle size of $110-140 \mu \mathrm{m}$, exhibits bulk and tapped densities of $0.3 \mathrm{~g} / \mathrm{mL}$ and $0.4 \mathrm{~g} / \mathrm{mL}$, respectively (Polyplasdone, 2013).

The performance of a dosage form is considered to be linked to the physical and chemical properties of its components. In this case, and as for other components of a formulation, crospovidone particle properties play an important role in the fabrication and performance of the dosage form. The knowledge of the relationships between the particle properties and their impact on the process is crucial for the development and manufacture of the dosage form (Parikh, 2013).

Effective superdisintegrants ideally provide not only disintegrant properties but also improved compressibility and compatibility and no negative impact on the mechanical strength of formulations. In particular, good compressibility and flow properties are desirable in a disintegrant.
Generally speaking, tablet quality is quantified in terms such as strength, weight, dimensions, and active pharmaceutical ingredient content; the required properties are produced through control of variables such as flowability and tabletability of the mix. This is achieved by addressing fundamental issues such as excipient choice and the concentration of each component in the final formulation (Barrios-Vazquez, Villafuerte-Robles, 2013).

The functional performance of tablet excipients is related to their physical, chemical and technological properties. It can be assessed using either powder versions of the excipients, tablets of pure excipients or formulations of a given drug. The first two levels correspond to a surrogate functionality that belongs to a pre-formulation phase. The knowledge of the surrogate functionality enables us to predict whether or not a particular excipient is likely to have the requisite functionality to produce a product that will meet the finished product specifications in all respects. The third level corresponds to the explicit functionality of the excipients to develop an appropriate formulation of a drug and an effective manufacturing process for the creation of a tablet (Díaz-Ramírez, Villafuerte-Robles, 2010).

Functionality is the property that is desirable in an excipient to assist in the manufacture and improve the conditions of manufacturing, quality or performance of the drug. Each formulation or product has its own requirements or functionality requirements for an excipient. This means that the functionality can only be determined in a batch and a specific product. However, it is possible that the functionality of the pure excipients could be determined as surrogate functionality. It is determined through physical and/or physicochemical properties which are critical to the typical uses of an excipient. It may also be determined using surrogate tests demonstrating the technological performance of the pure excipients without a formulation or application to a specific drug and product. Among the surrogate functional tests concerning technological performance, there are compactibility curves, ejection pressure curves and curves displaying the disintegration properties of the individual excipients.

Most of the materials used in the industry exhibit various mechanical properties. Understanding these properties will help to make a formulation decision, such as choosing the types of excipients to use, and the final evaluation of the dosage form (Parikh, 2013).

Among other factors, powders flow properties have been traditionally characterized using a flow through an orifice tester or an angular shear cell. The angle of repose, Carr's compressibility index $(\mathrm{CI})$ and the Hausner ratio are further commonly used as markers of powder flowability (Nalluri, Kuentz, 2010). 
"Although some would consider angle of repose, compressibility index, and flow through an orifice to be 'primitive', there are enough data in the literature to indicate that they can be correlated with manufacturing experience and because of that they are of some value" (Rios, 2006).

Polyplasdone crospovidones are considered free-flowing materials and the $\mathrm{CI}$ has been reported for Polyplasdone XL as 29\% (Fujii et al., 2005), 22\% (Quadir, Kolter, 2006) and 33\% (Bühler, 2005), while Polyplasdone XL10 was reported to have a CI of 31\% (Quadir, Kolter, 2006), 29.9\% (Jain et al., 2010) and 40\% (Polyplasdone, 2013). These different results have been found in the literature or calculated from published data for bulk and tapped densities and vary because of the different methods used to assess the data or due to changes in the excipient properties between different batches.

Nevertheless, compressibility indexes from the same source always display greater values (lesser fluidity) for polyplasdone XL10 than for XL (greater fluidity). The results are mostly attributed to the particle size of polyplasdones.

One of the procedures used to characterize and classify the mechanical properties of pharmaceutical materials involves compact testing to derive indexes of tableting performance (Nordström et al., 2011). Among them, enhanced tablet tensile strength with increasing compaction pressure has been used. This showed a progressive increase in tensile strength up to a certain limit. Thereafter, with increasing compaction pressure, the tablet tensile strength was shown to level out. The overall compactibility profile tended to be sigmoid in shape (Fichtner et al., 2008). Compactibility profiles with sigmoid shape have been described using an equation based on the Weibull distribution (Eq. 1) (Castillo, Villafuerte, 1995a; Castillo, Villafuerte, 1995b). Recently, this model has been used to describe the compactibility of celluloses as indicative of their functionality as tablet excipients (Díaz-Ramírez, Villafuerte-Robles, 2010).

$$
\ln (-\ln (1-\mathrm{D} / \mathrm{Dmax}))=n * \ln P c+I \quad \text { Eq. } 1
$$

where $D$ denotes the tablet's hardness or crushing strength, Dmax the maximal crushing strength attained, $P c$ the compaction pressure, $n$ the slope of the curve and $I$ the intercept of the curve.

Tablets must have sufficient mechanical strength to resist crumbling or breaking when being handled and processed, especially during packaging. Tablet hardness is therefore important and has practical relevance (Ilića et al., 2010).
The excipients in a drug product determine the characteristics of the final product that should remain within certain limits in order for quality assurance to approve its release. The quality control attributes (QCAs) of a dosage form are linked to raw material attributes and process parameters. Linking raw material attributes to CQAs is a valuable science-based process that can aid in identifying which material attributes and process parameters critically affect the product (Miinea et al., 2009).

The functionality of crospovidones can vary according to the formula in which they are used. In this sense, it can be useful to test their functionality with tablets of drugs that do not disintegrate easily, such as amoxicillin, and with excipients representing water soluble (lactose) and water insoluble (calcium phosphate) materials. These materials are known to display an important degree of difference in the effectiveness of superdisintegrants (López-Solis, Villafuerte-Robles, 2001).

The objective of this study was to provide a bibliographic overview of the quantitative functionality of crospovidones in promoting tablet disintegration and to evaluate their functionality as excipients for direct compression supporting the formula compactibility and powder flowability.

\section{MATERIAL AND METHODS}

\section{Material}

The materials used in this study were Polyplasdone XL (batch 03100261478) and Polyplasdone XL10 (batch 03100262509) obtained from Ashland-ISP Technologies Inc., amoxicillin trihydrate obtained from Química Alkano, magnesium stearate and Pharmatose M200 obtained from Helm, and calcium phosphate from DROTASA. The drug and the excipients were used as received.

\section{Methods}

\section{Powders to be processed}

The drug and excipients were evaluated as individual powders and as mixtures. Powders corresponding to $30 \mathrm{~g}$ of the mixtures were weighed and mixed in a twin shell blender for $25 \mathrm{~min}$, at $26 \mathrm{rpm}$. Polyplasdones XL and XL10 were mixed separately with magnesium stearate proportions of $1 \%$ and $2 \%$, calcium phosphate proportions of $97 \%, 95 \%$ and $90 \%$, Pharmatose M200 proportions of $97 \%, 95 \%$ and $90 \%$, and mixtures of amoxicillin containing $1 \%$ and $2 \%$ magnesium stearate at proportions of $95 \%$ and $97 \%$. 


\section{Disintegration time}

Tablets obtained as in the subtitle compactibility were used to determine the disintegration time. Disintegration time was measured using $900 \mathrm{~mL}$ water at $37^{\circ} \mathrm{C}$, using the USP disintegration test apparatus without the discs (TEMSA-Mexico). The disintegration time was taken as the time required for each one of three tablets to pass completely through the screen or the time required to obtain a soft mass without any hard agglomerates. The value is registered as the average of three tablets.

\section{Compactibility}

Tablets weighing $150 \mathrm{mg}$ were compacted for $10 \mathrm{~s}$ in a hydraulic press, at a series of compaction pressures from $27 \mathrm{MPa}$ to $207 \mathrm{MPa}$ and using $8 \mathrm{~mm}$ circular flat-shaped punch and die. Tablet crushing strength was measured in triplicate, registering the results as an average. For this purpose, a tablet hardness tester Erweka TBH30 was used. The procedure involved placing each tablet diametrically between two flat surfaces and applying pressure until the tablet breaks down. The results were expressed as compactibility curves against the compaction pressure used to obtain the tablets.

\section{Powder flow}

The equipment used to assess the powder flow is of our own fabrication and similar to that used to determine the tap density of powders (Kibbe, 2000; Villafuerte, 2001). The tapper was adjusted at a rate of 50 taps per minute and the graduated cylinder was elevated up to a height of $15 \mathrm{~mm}$. This device uses a $100 \mathrm{~mL}$ graduated cylinder joined to a glass funnel with an orifice of $6 \mathrm{~mm}$ that can be closed using a glass rod. Once the sample has been weighed and placed in the closed funnel, the rod is removed and the device starts. The time required to empty $25 \mathrm{~g}$ of the powder from the funnel, through the funnel orifice, was used to calculate the speed of the powder flow. The registered results are the average of 5 repetitions with the same sample. The powders were sieved through a number 20 mesh after each repetition.

\section{Bulk and tapped density}

The bulk $\left(\rho_{b}\right)$ and tapped density $\left(\rho_{t}\right)$ of powders were determined using the above-mentioned tapping machine $(\mathrm{n}=5)$. A $100 \mathrm{~mL}$ measuring cylinder was filled with $25 \mathrm{~g}$ of sample. The volumes were recorded at the beginning (bulk volume) and after 10 taps. The process continued until 3 successive volume measurements remained constant (tapped volume). The bulk density was calculated as the ratio of mass and initial volume or bulk volume, while the tapped density was calculated as the ratio of mass and tapped volume. The Carr's Index or compressibility index (CI-\%) (Mehta et al., 2012) was calculated according to the following equation:

$$
\text { Compressibility Index }=\frac{\rho t-\rho b}{\rho t} * 100 \quad \text { Eq. } 2
$$

\section{RESULTS AND DISCUSSION}

\section{Effect of crospovidones on tablet disintegration}

\section{Disintegration of pure crospovidone tablets}

Figure 1 depicts the effect of an increasing compression pressure on the disintegration time of crospovidones tablets. Compression pressure increased the disintegration time of pure Polyplasdone XL tablets, even though all of the tablets disintegrated quite rapidly, within $2 \mathrm{~min}$. On the other hand, disintegration times of Polyplasdone XL10 tablets remained practically unchanged with an increasing compression pressure. The addition of magnesium stearate reduced the disintegration times of both crospovidones tablets. The compression force on crospovidone tablets containing magnesium stearate had practically no effect.

The effect of magnesium stearate on the tablets' disintegration time has been ascribed to a loss of affinity for water of crospovidone tablets due to the greasy hydrophobic domains of the lubricant and to a loss of coherence of the tablets because of the mechanical weakness of the same greasy domains; the loss of coherence of the tablets prevails over the loss of affinity for water. As will be shown in the following paragraphs, Polyplasdone XL tablets compacted at about $180 \mathrm{MPa}$ showed a loss of tablet hardness of about $48 \%$ after the addition of $2 \%$ magnesium stearate. This produced a decrease of about $35 \%$ in the observed disintegration time. In the same way, a loss of tablet hardness of $35 \%$ of Polyplasdone XL10 produced a decrease of $23 \%$ in the disintegration time (Figure 1).

The in vitro disintegration time of Polyplasdone XL10 was found to be almost twice that of Polyplasdone $\mathrm{XL}$. The in vitro disintegration time was rapid for tablets containing Polyplasdone XL and somewhat delayed for tablets containing Polyplasdone XL10.

Figure 2 depicts tablets of crospovidones and their admixtures with magnesium stearate, considering the disintegration times calculated by regression for a compaction pressure of $178 \mathrm{MPa}$. Polyplasdones XL and XL10 tablets showed the same trend towards decreasing disintegration times as the magnesium stearate proportion 


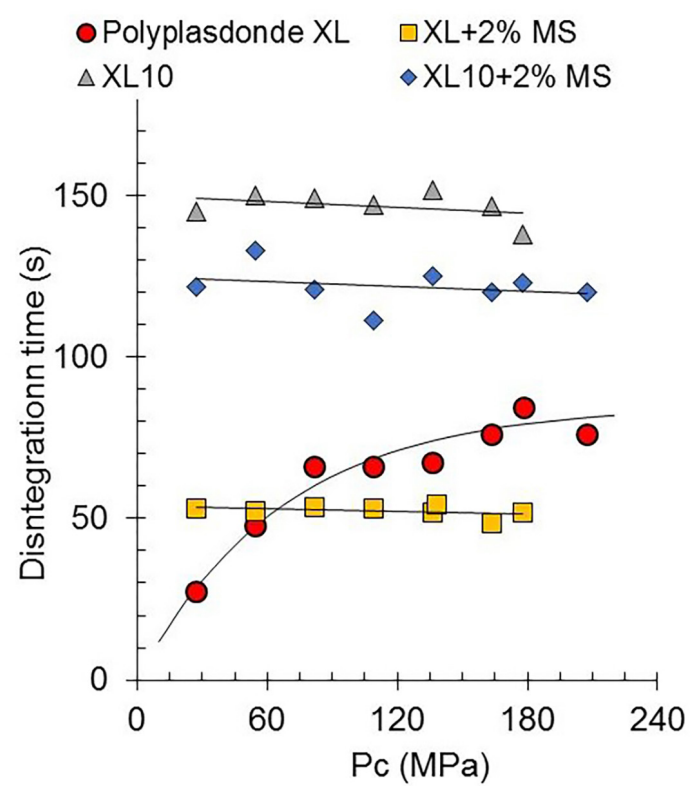

FIGURE 1 - Effect of magnesium stearate on the disintegration profile of the crospovidones tablets Polyplasdones XL and XL10.

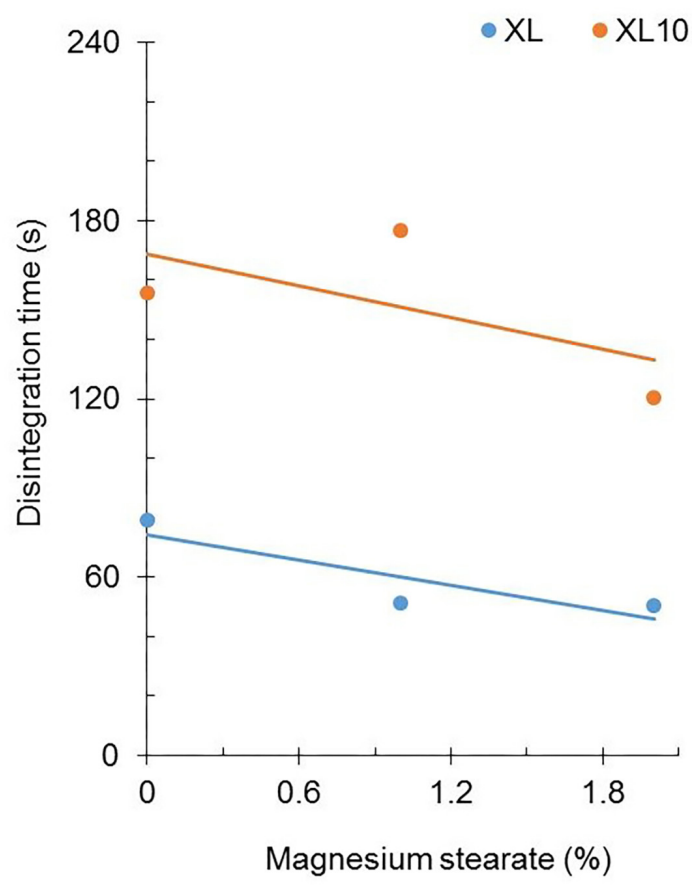

FIGURE 2 - Effect of magnesium stearate on the disintegration time of Crospovidones, Polyplasdones XL and XL10 tablets. Points calculated by regression for $\mathrm{Pc}=178 \mathrm{MPa}$.

increased. The faster disintegration of Polyplasdone XL tablets may be due to a greater average particle size (110-140 $\mu \mathrm{m})$ and a lower compactibility compared to Polyplasdone XL10 $(25-40 \mu \mathrm{m})$ (Polyplasdone, 2013).
The greater particle size allows a greater powder bed porosity and tablet porosity and faster water uptake from the medium, swelling and burst effect. Moreover, it seems that during compaction, the larger Polyplasdone XL particles become more deformed than the smaller ones of Polyplasdone XL10. After contact with water, Polyplasdone XL particles recover their normal structure, producing a greater force of expansion and tablet disintegration. Moreover, and as will be shown later, Polyplasdone XL tablets display lower compatibilities, thereby enabling shorter disintegration times.

The values of disintegration time of pure Polyplasdones tablets, calculated at a compaction pressure of $178 \mathrm{MPa}$, can be used as a measure of functionality, or rather a surrogate functionality. In this way, the functionality of Polyplasdone XL corresponds with a disintegration time of $79 \mathrm{~s}$, while that of Polyplasdone XL10 corresponds with a disintegration time of $156 \mathrm{~s}$. This indicates greater functionality as the disintegration time is shorter.

The greater disintegrability of Polyplasdone XL tablets over that of Polyplasdone XL10 has been previously observed in tablets of physical mixtures and solid dispersions of fenofibrate containing superdisintegrants. Tablets of solid dispersions containing Polyplasdone XL displayed an average disintegration time of $24.0 \mathrm{~min}$ while tablets containing Polyplasdone XL10 showed an average disintegration time of $30.6 \mathrm{~min}$ (Srinarong et al., 2009).

The disintegration behavior of crospovidones has been consistently observed in some other cases. Tablets of Ludipress LCE showed disintegration times of 73s for tablets containing Polyplasdone XL, while tablets of the same formulation containing Polyplasdone XL10 displayed disintegration times of $116 \mathrm{~s}$. In the same way and using a second formulation containing aspirin, caffeine and paracetamol, tablets containing Polyplasdone XL showed a disintegration time of 12 min while tablets containing Polyplasdone XL10 showed a disintegration time of 22 min (Quadir, Kolter, 2006).

As can be seen, the functionality or disintegration properties of Polyplasdone XL are superior to those of Polyplasdone XL10. An average of the above-mentioned cases reveals that the disintegration times of tablets containing Polyplasdone XL are 48\% (23-71\%) shorter than those of tablets containing Polyplasdone XL10.

\section{Effect of crospovidones on tablet disintegration}

Among the physical properties of accompanying particles that affect the effectiveness of a disintegrant, solubility is considered of great importance. The solubility of the tableting mixture in water (drug and filler) has a 
definite influence on the effectiveness of disintegrants; disintegrants are more effective in insoluble mixtures. Calcium phosphate placebo tablets with $4 \%$ crospovidone have been observed to disintegrate significantly faster than tablets containing lactose (Mohamed et al., 2012).

The effects of tablet formulation solubility and hygroscopicity on the dissolution efficiency of crospovidone in tablets indicate that highly soluble and/ or hygroscopic ingredients decrease the effectiveness of disintegrants in promoting in vitro dissolution (Roche Johnson et al., 1991). However, in other cases, only hygroscopicity remained valid to decrease the efficiency of the disintegrants (Gordon, Chowhan, 1987).

Lactose and dicalcium phosphate have been used as fillers by many researchers, representing soluble and insoluble tablet matrices, respectively (Mrudula, Derle, 2011). Therefore, in order to better distinguish between the functionalities of different crospovidones, these different diluents were used.

Crospovidones lowered the disintegration time of Pharmatose M200 tablets after the addition of 3\% disintegrants. However, the disintegration time of tablets increased after the addition of greater proportions of the disintegrants (Figure 3). This can be ascribed to a double and counteracting effect of crospovidones, acting as disintegrants but also as tablet agglutinants. At the beginning, the disintegrant effect of crospovidones predominates, while the predominance of its effect as agglutinant elevates progressively with increasing proportions of crospovidones.

The above-mentioned effect has been previously observed in Avicel 200 tablets containing Polyplasdone XL10 proportions between $0 \%$ and $12 \%$. The disintegration times began at 90 s for pure Avicel tablets, reached a minimum at 7\% Polyplasdone XL10 (9s) and thereafter increased up to $13 \mathrm{~s}$ with a Polyplasdone proportion of 12\% (Kasliwal, Singh, 2011).

Once again, the disintegration times of tablets containing Polyplasdone XL are about a half (average $\approx 9 \mathrm{~s}$ ) those containing Polyplasdone XL10 (average $\approx 20 \mathrm{~s}$ ). Although there is an improvement in tablet disintegration after the addition of $3 \%$ crospovidones, the disintegration times are within the same range as those reported for Pharmatose M200 tablets. Pure Pharmatose M200 tablets correspond with zero crospovidone, as depicted in Figure 3.

The effect of crospovidones on Pharmatose M200 tablet disintegration is relative to lactose solubility. Lactose is a freely water soluble substance. The solubility of lactose in water is $180 \mathrm{~g} / \mathrm{L}$ at $20^{\circ} \mathrm{C}$ and $18.9 \mathrm{~g}$ at $25^{\circ} \mathrm{C}$, per $100 \mathrm{~g}$ solution. Lactose is freely but slowly soluble in water (Lactose, 2013; Machado et al., 2001).

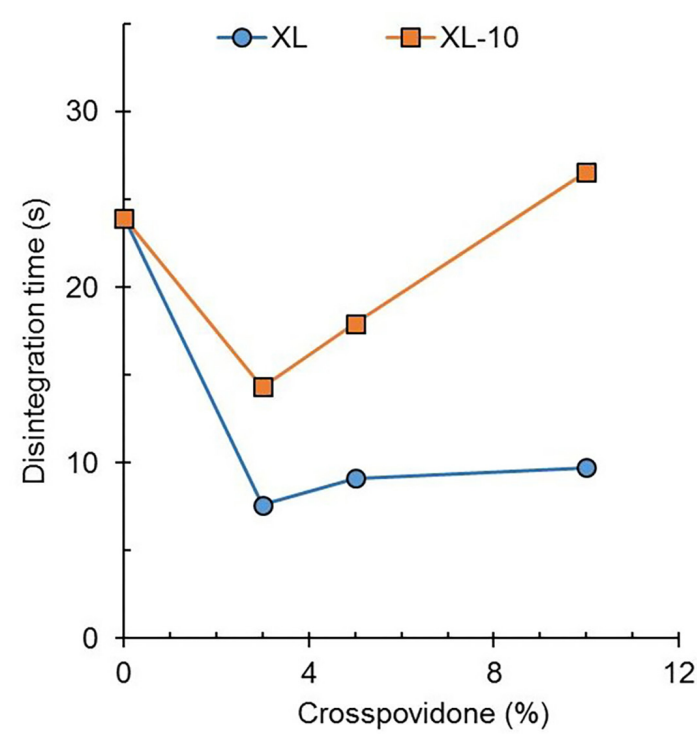

FIGURE 3 - Effect of crospovidones Polyplasdones XL and XL10 on the disintegration time of Pharmatose M200 tablets. Points calculated for a compaction pressure of $163 \mathrm{MPa}$.

On the other hand, the improvement in disintegration time produced by crospovidones on calcium phosphate tablets is more important (Figure 4). Tablets of calcium phosphate do not disintegrate completely after $30 \mathrm{~min}$. After the addition of crospovidones, the disintegration time is reduced to an average of about $4 \mathrm{~s}$.

The differential effect of crospovidones on the disintegration of Pharmatose M200 and calcium phosphate tablet matrices has been ascribed to their water solubility. It is believed that a water soluble excipient competes with the disintegrant for the available water inside the tablet. In fact, it has been observed that Starch 1500, working as an active disintegrant, and Pharmatose DCL11, as a passive dissolving disintegrant, displayed mutual inhibition to promote norfloxacin tablet dissolution. On the other hand, the addition of mixtures of Starch 1500 and the insoluble diluent calcium phosphate potentiated the disintegrant effect to promote norfloxacin dissolution (López-Solis, Villafuerte-Robles, 2001).

The results obtained in this study agree with the above-mentioned data registered in the literature. An insoluble excipient like calcium phosphate, with a solubility of $20 \mathrm{mg} / \mathrm{L}$ water (Calcium and Water, 2013), favors the disintegrant proficiency of crospovidones compared to a soluble excipient like Pharmatose M200.

Of particular note is the fact that the two different crospovidones do not show the previously mentioned greater ability of Polyplasdone XL over Polyplasdone XL10 to disintegrate tablets. The disintegrant ability of both excipients is practically the same on tablets of the 


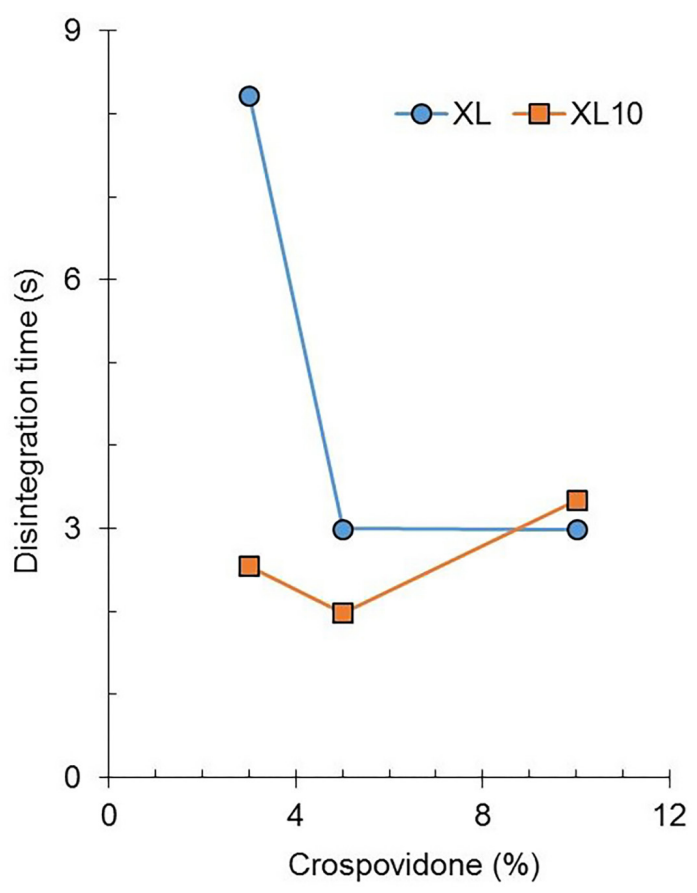

FIGURE 4 - Effect of crospovidones Polyplasdone XL and XL10 on the disintegration time of Calcium Phosphate tablets, calculated for $\mathrm{Pc}=163 \mathrm{MPa}$.

water insoluble calcium phosphate. This can be attributed to the exceptionally fast disintegration times.

As previously seen for Pharmatose M200 tablets, the addition of crospovidones to calcium phosphate tablets decreases the disintegration time. However, after attaining a minimum, increasing proportions of the added crospovidones produced increasing disintegration times.

Figure 5 depicts the effect of compaction pressure and crospovidones proportion on the disintegration time of amoxicillin tablets containing a lubricant. In this case, tablet disintegration times were increased in tablets containing a greater proportion of the lubricant. Moreover, the disintegration times of tablets containing $5 \%$ crospovidones exhibit shorter disintegrations times than tablets containing 3\% disintegrant.

The disintegration profiles of amoxicillin tablets (Figure 5) can be ascribed to an increasing deformation of crospovidone particles, with the subsequent stronger recovery after interaction with water, and to decreasing tablet porosity as the compaction pressure increases. Polyplasdone was reported to exhibit a high capacity to retain deformation during post-compression (Zhao, Augsburger, 2005). The rapid swelling and disintegration of these tablets upon wetting may be partly attributed to the recovery of deformation. These counteracting effects produce a disintegration profile attaining first a

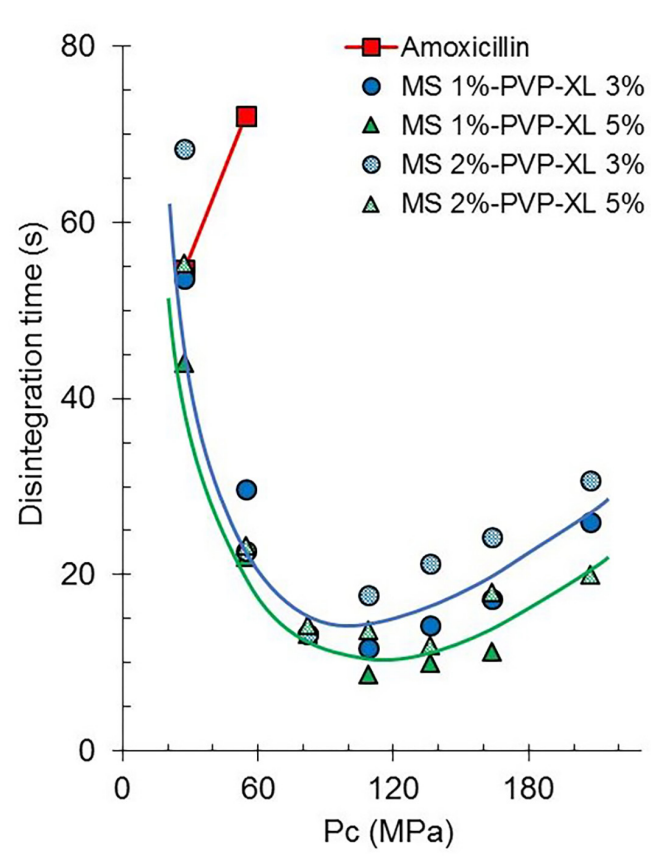

FIGURE 5 - Effect of Polyplasdone XL and compaction pressure on the disintegration profile of Amoxicillin tablets containing $1 \%$ and $2 \%$ magnesium stearate.

minimum and then an increasing disintegration time as the compaction pressure increases.

Considering an average disintegration time of amoxicillin tablets containing different proportions of magnesium stearate $(0,1$ and $2 \%)$ at a compaction pressure of $163 \mathrm{MPa}$, Figure 6 depicts the effect of

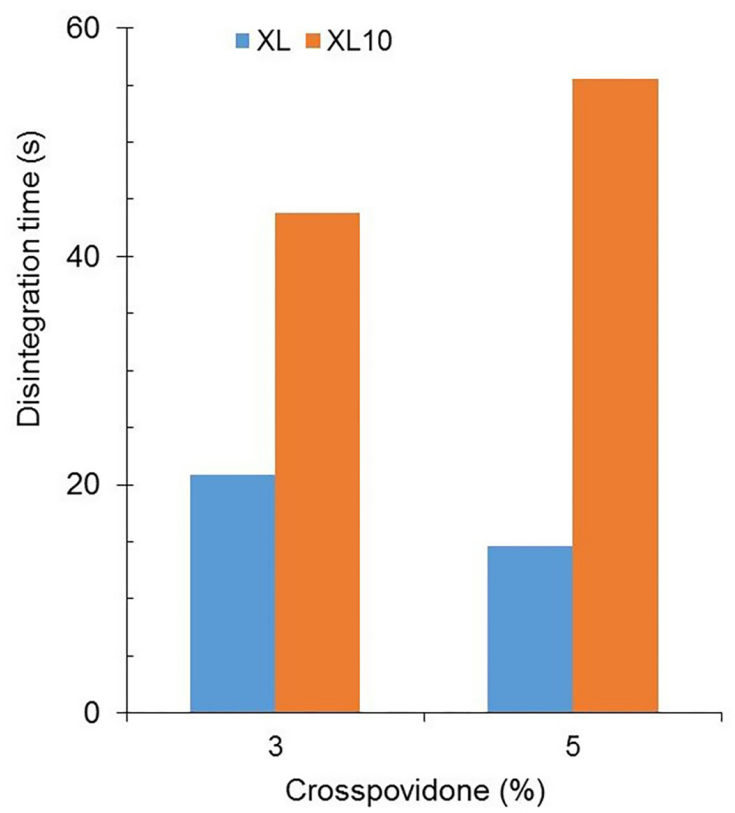

FIGURE 6 - Effect of crospovidones on the average disintegration time of amoxicillin tablets containing magnesium stearate. Calculated for tablets compacted at $163 \mathrm{MPa}$. 
the type of crospovidone on the disintegration time of amoxicillin tablets. In the same way as seen for Pharmatose, the disintegration times are greater in tablets containing Polyplasdone XL10 (average of $50 \mathrm{~s}$ ) compared to tablets containing Polyplasdone XL (average of $18 \mathrm{~s}$ ). It is noteworthy that the higher disintegration times of Pharmatose M200 and amoxicillin tablets containing Polyplasdone XL10 over those of tablets containing Polyplasdone XL are in line with the higher crushing strengths displayed by tablets containing Polyplasdone XL10. These data will be shown later when the compactibility of crospovidones is discussed.

Similar disintegration results were observed for oral disintegrating Cetirizine HCl-coated granule tablets containing different amounts of Polyplasdone XL and XL10 (Douroumis et al., 2011). Tablets containing Polyplasdone XL10 showed approximately 22\% higher disintegration times (average of $7.26 \mathrm{~s}$ ) than those containing Polyplasdone XL (average of $5.67 \mathrm{~s}$ ). This occurs in spite of cetirizine $\mathrm{HCl}$ tablets containing Polyplasdone XL, which show a compactibility that is approximately $12 \%$ higher (average of $4.79 \mathrm{kP}$ equivalent to $47.0 \mathrm{~N}$ ) than those containing Polyplasdone XL10 ( $4.25 \mathrm{kP}$ equivalent to $41.7 \mathrm{~N})$. In such work, tablets were obtained at compaction forces of $4 \mathrm{kN}, 8 \mathrm{kN}, 10 \mathrm{kN}$ and $12 \mathrm{kN}$, containing $2 \%, 5 \%, 10 \%$ and $20 \%$ Polyplasdone.

The disintegration times of amoxicillin tablets are higher than those of Pharmatose M200 tablets, although lactose is much more water soluble $\left(180 \mathrm{~g} / \mathrm{L}\right.$ at $\left.20^{\circ} \mathrm{C}\right)$ than amoxicillin (3.43 g/L water) (Lactose, 2013; Machado et al., 2001). This apparent failure of the statement "the greater the overall hygroscopicity and solubility of the tablet formulation, the larger the decrease in the efficiency of the disintegrant" can be ascribed to the fact that lactose is slowly soluble in water. Moreover, the greasy hydrophobic magnesium stearate particles contained by amoxicillin tablets, that are not present in Pharmatose M200, also contribute to increased disintegration times.

In conclusion, the functionality of Polyplasdone XL10 as a disintegrant (average disintegration time (DT) $=156 \mathrm{~s}$ ) is about a half that of Polyplasdone XL (average $\mathrm{DT}=79 \mathrm{~s}$ ), mostly due to its smaller particle size, the smaller tablet porosities produced and the increased tablet hardness. Disintegration times of crospovidones decrease after the addition of magnesium stearate, presumably because of a loss of coherence of the tablets. Increasing proportions of crospovidones first reduce the disintegration time of different tablet matrices and then increase the disintegration times. This is probably due to their counteracting disintegrant and agglutinant properties. Increasing compaction pressures first decrease and then increase the disintegration time of amoxicillin tablets. This is attributed to a progressive decrease of porosity and increasing deformation of crospovidone particles, which is recovered after contact with water.

\section{Effect of crospovidone on tablets compactibility}

In addition to the active pharmaceutical ingredients, tablets also contain functional ingredients that are necessary to bulk out the actives or modify the quality and processing properties of the tablet. Various excipients aid in compacting the drug during the tableting procedure as they do not always possess good compactibility. Important tableting process parameters include a high capacity for compression and consolidation of materials.

\section{Compactibility of crospovidone tablets}

The tablet crushing strength increased up to a certain limit by increasing compaction pressures; thereafter, the tablet crushing strength leveled out. Compactibility profiles with a sigmoid shape, like those shown in Figure 7, have been described with an equation based on the Weibull distribution (Eq. 1).

The compactibility curves obtained describe the relationship between the hardness or crushing strength of the tablets and the compaction pressure used to obtain them. Figure 7 shows the experimental points and calculated regressions, according to Eq. 1, for the

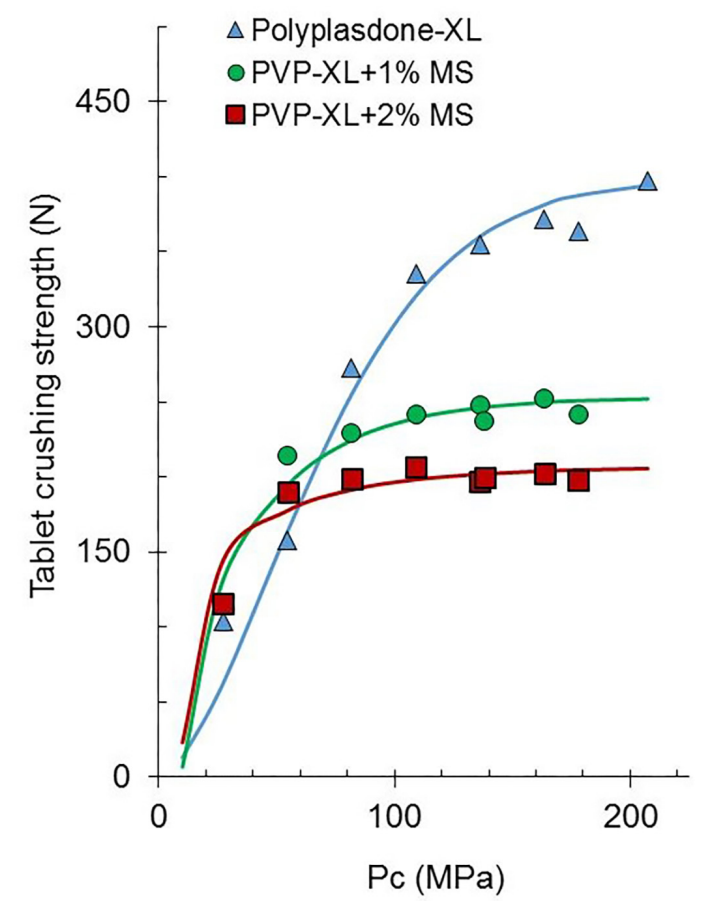

FIGURE 7 - Effect of magnesium stearate on the compactibility profile of Polyplasdone XL tablets. 
compactibility of Polyplasdone XL and its admixtures with magnesium stearate.

The compactibility of Polyplasdone XL $(D \max =392 \mathrm{~N})$ and polyplasdone XL10 $(\operatorname{Dax}=314 \mathrm{~N})$ tablets is high compared to some other excipients, such as GalenIQ 720 (agglomerated isomalt), with a Dmax of $134 \mathrm{~N}$, and Helmcel 200 (microcrystalline cellulose type 102) with a Dmax of 357 N. These values of Dmax were obtained using tablets with the same geometry and weight and measured by the same method (Samayoa-Sandoval, Villafuerte-Robles, 2013). These values are considered the surrogate functionalities of the excipients as agglutinants for direct compression. In this sense, Polyplasdone XL and XL10 display functional properties not only as a disintegrant but as a direct compression agglutinant. Their functionality as a direct compression agglutinant is similar to that of microcrystalline cellulose type 102 (Helmcel 200) and almost more than the double of that of GalenIQ 720.

Crospovidones are considered more compactible than other superdisintegrants, producing tablets with high breaking force and low friability. It has been found that Polyplasdone crospovidones possess significantly higher breaking force than superdisintegrants such as croscarmellose sodium and sodium starch glycolate (Polyplasdone, 2013).

After addition of the lubricant magnesium stearate, the tablet crushing strength of both crospovidones shows a tendency to decrease as the proportion of the lubricant increases (Figure 8). This effect is common for polymeric materials compacting by particle deformation. The compactibility of Polyplasdone XL, determined as the maximal tablet crushing strength (Dmax), is $392 \mathrm{~N}$ and reduces its magnitude to $252 \mathrm{~N}$ after the addition of $1 \%$ magnesium stearate and to $206 \mathrm{~N}$ after the addition of $2 \%$ magnesium stearate.

The mechanism behind a decrease in tablet crushing strength is thought to be a lubricant coating the particles of drugs and excipients, interrupting interparticle bonding. Increasing proportions of lubricants more efficiently interrupt this bonding, reducing the tablet crushing strength to a greater extent. Materials that are compacted by particle deformation are more affected, while materials that are compacted by fragmentation are less or not at all affected due to the formation of new clean surfaces after fragmentation.

Magnesium stearate is a commonly used lubricant in pharmaceutical formulations. However, some pharmaceutical excipients have shown sensitivity to this material when compacted. It has been found that this sensitivity decreases as the ductility of the materials decreases and vice versa. Materials such as Starch 1500 displayed a lubricant sensitivity as high as 0.53 , while this was only 0.31 for a type of rice starch, equating to a reduction of tablet hardness of $51 \%$ and $31 \%$, respectively, after lubrication of the powders. These values were determined using a lubricant content of 1\% (Ahmad et al., 2012).

The average lubricant sensitivity of Polyplasdones XL and XL10, expressed as the fraction or percentage of the reduction of the tablet hardness, is 0.226 and 0.416 in the presence of $1 \%$ and $2 \%$ of magnesium stearate, respectively. These values were determined by taking the maximal tablet hardness (Dmax) calculated from compactibility profiles as a reference (Figure 7). This showed a decrease of compactibility of $22.6 \%$ and $41.6 \%$, respectively. These results are in line with materials compacting by plastic deformation. The average lubricant sensitivity of crospovidones, containing $1 \%$ magnesium stearate $(22.6 \%)$, is significant but smaller than that observed by Starch 1500 (51\%) and rice starch (31\%).

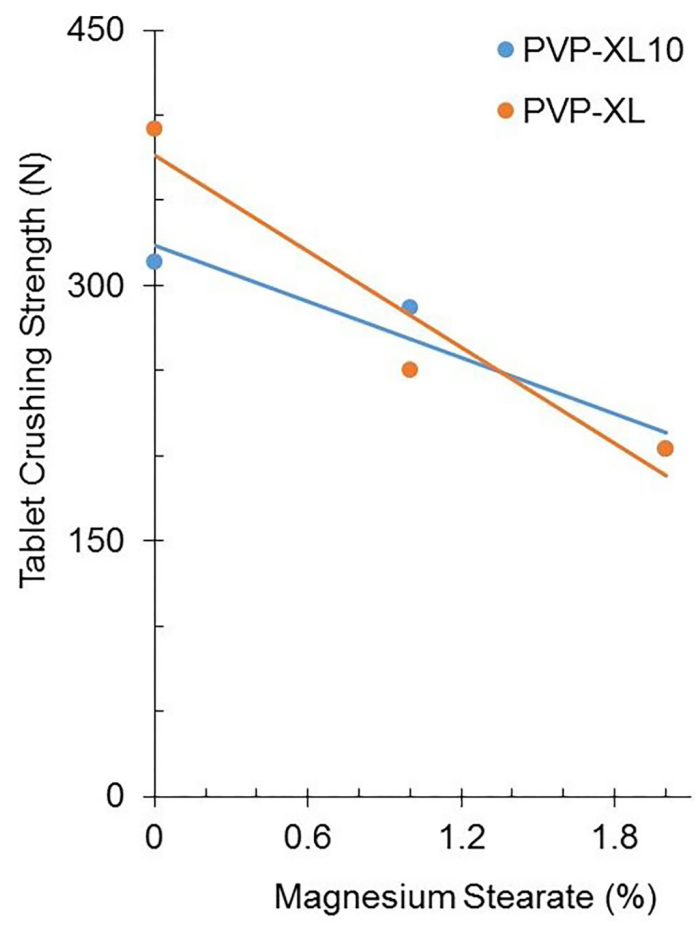

FIGURE 8 - Effect of magnesium stearate on the calculated compactibility $(\mathrm{Pc}=207 \mathrm{MPa})$ of Crospovidones, Polyplasdone $\mathrm{XL}$ and XL10.

\section{Effect of crospovidone on compactibility of tablets}

Pharmatose M200 tablets containing varying amounts of crospovidones were prepared under the same conditions of compaction pressure as those of the pure disintegrants. The tablet crushing strength was also 
determined under the same measurement conditions. Increasing proportions of the cross-linked polymers, up to $10 \%$, increased the tablet crushing strength; tablets containing Polyplasdone XL displayed lower compactibilities than tablets containing Polyplasdone XL10. Figure 9 depicts the maximal tablet crushing strength $(\mathrm{Pc}=207 \mathrm{MPa})$ as a function of the crospovidone content, which was calculated by regression.

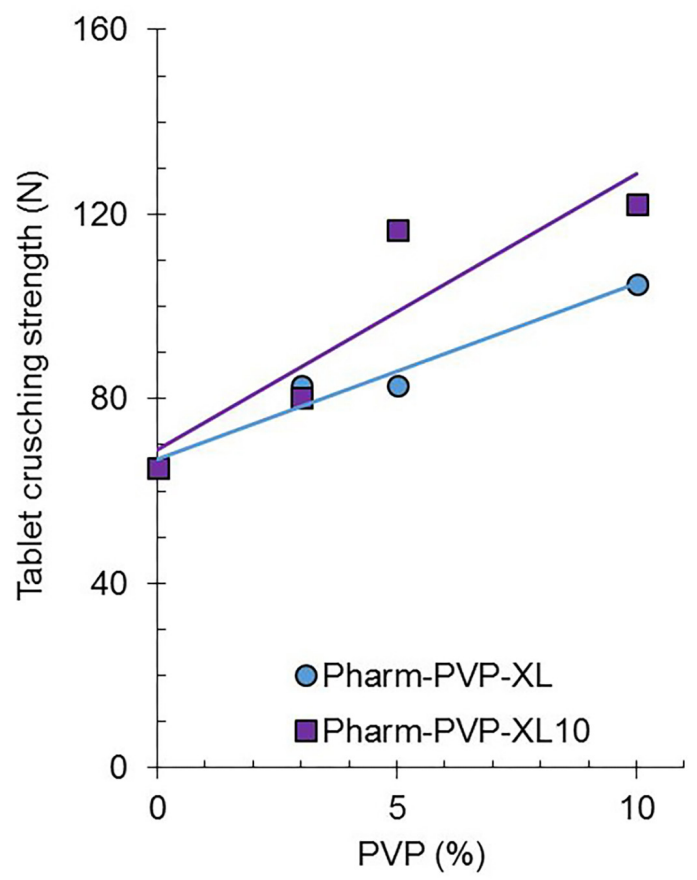

FIGURE 9 - Effect of crospovidones Polyplasdones XL and XL10 on the compactibility of Pharmatose M200. Points calculated by regression for $\mathrm{Pc}=207 \mathrm{MPa}$.

The explicit functionality of Polyplasdone XL, as a direct compression agglutinant of a water soluble matrix of Pharmatose M200, is defined by compactibility improvement obtained. Pharmatose M200 tablets increase their tablet crushing strength by about $3.8 \mathrm{~N}$ per percentage point of added Polyplasdone XL. Also, the addition of every percentage point of Polyplasdone XL10 to Pharmatose M200 tablets improves their compactibility by about $6.0 \mathrm{~N}$. Related to the original compactibility of Pharmatose M200 (65 N), this means an increase in compactibility of about $5.8 \%$ and $9.2 \%$, respectively.

A similar functionality of Polyplasdone to improve tablet compactibility has been observed by frusemide tablets. Polyplasdone improved the tablet compactibility, in a range of 4-7 $\mathrm{N}$ per percentage point of the superdisintegrant added, which was dependent on the compaction force used to generate the tablets. Considering a compaction pressure of 10 ton the original compactibility was $203 \mathrm{~N}$ and increased by about $4.8 \mathrm{~N}$ per percentage point crospovidone added. This is equivalent to an increase of about $2.3 \%$. These results were calculated from published data (Chaulang et al., 2012).

In the same way, Polyplasdone XL also improved the compactibility of meclizine tablets $\left(3.7 \mathrm{~kg} / \mathrm{cm}^{2}\right)$ by $0.1 \mathrm{~kg} / \mathrm{cm}^{2}$ per percentage point of the added disintegrant. This is equivalent to an increase of about $2.7 \%$ (Goyani et al., 2012).

The effect of Polyplasdone on the tablet crushing strength of a water insoluble matrix such as calcium phosphate is depicted in Figure 10. Calcium phosphate matrices also increase their tablet compactibility after the addition of Polyplasdone. However, the increase is much smaller than that seen for matrices of Pharmatose M200. In this case, the tablet crushing strength increases by $0.8 \mathrm{~N}$ and $1.2 \mathrm{~N}$ per percentage point of the added crospovidones Polyplasdone XL and XL10, respectively. Considering the original compactibility of calcium phosphate tablets $(78 \mathrm{~N})$, this increased by about $1.0 \%$ and $1.5 \%$ per percentage point of crospovidone added, respectively.

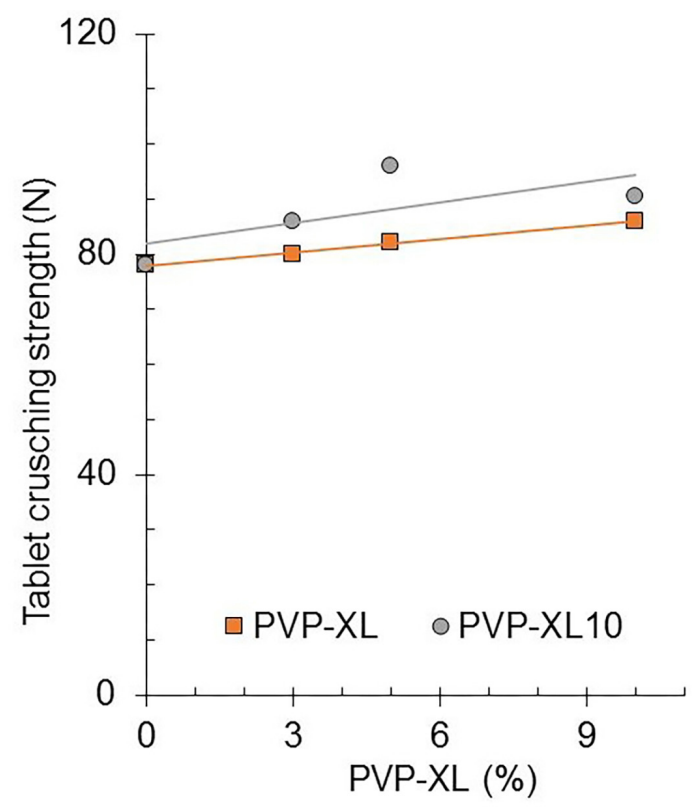

FIGURE 10 - Effect of crospovidones Polyplasdone XL and XL10 on the compactibility of Calcium Phosphate. Points calculated for $\mathrm{Pc}=207 \mathrm{MPa}$.

As can be seen in Figure 11, crospovidones increase the compactibility of amoxicillin tablets. This figure displays the experimental points and the curves calculated by regression according to eq. 1 for amoxicillin tablets and tablets of amoxicillin with 5\% Polyplasdone XL and 2\% magnesium stearate added. The D $\max$ value of amoxicillin 


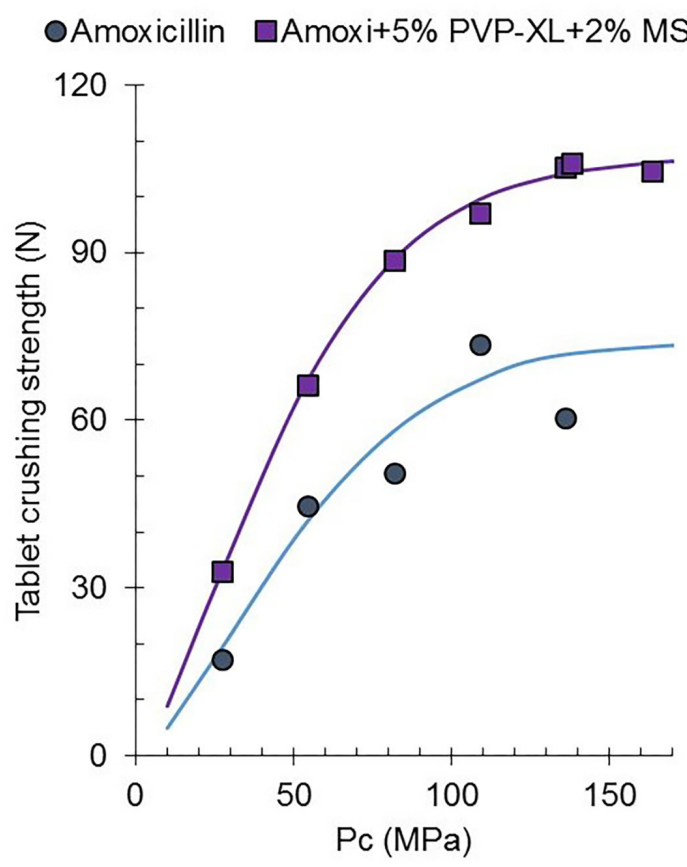

FIGURE 11 - Effect of 5\% Polyplasdone XL on the compactibility profile of amoxicillin tablets containing $2 \%$ magnesium stearate.

tablets increases from about $72 \mathrm{~N}$ to $105 \mathrm{~N}$ after the addition of Polyplasdone XL and magnesium stearate.

Figure 12 depicts the effect of crospovidones on the compactibility of amoxicillin tablets, expressed as the average compactibility calculated by regression for $\mathrm{Pc}=136 \mathrm{MPa}$. The functionality of crospovidones Polyplasdone XL and XL10 to increase the compactibility of amoxicillin tablets is about $9 \mathrm{~N}$ and $12 \mathrm{~N}$ per percentage point of Polyplasdone XL and XL10 added, respectively. This equates to an increase in compactibility of amoxicillin tablets $(59 \mathrm{~N})$ of $15 \%$ and $20 \%$ per point of crospovidone added, respectively.

The absolute values, as well as the relative ones, with regard to the improvement in compactibility produced by crospovidones are higher for amoxicillin tablets (average of $10.5 \mathrm{~N} ; 17.5 \%$ ), followed by Pharmatose M200 tablets (average of $4.9 \mathrm{~N} ; 7.5 \%$ ) and calcium phosphate tablets (average of $1.0 \mathrm{~N} ; 1.2 \%$ ).

The agglutinant effect of Polyplasdone depends on the tablet matrix and can be more or less important. Anyway, Polyplasdone has shown a positive effect on tablet hardness, irrespective of the concentration used. However, it has been reported that increasing proportions of the cross-linked polymer (1-10\%) did not influence crushing force or the friability of acetaminophen tablets (Salem et al., 1995).

According to the presented data, Polyplasdone XL10 displays a mostly greater positive effect on compactibility

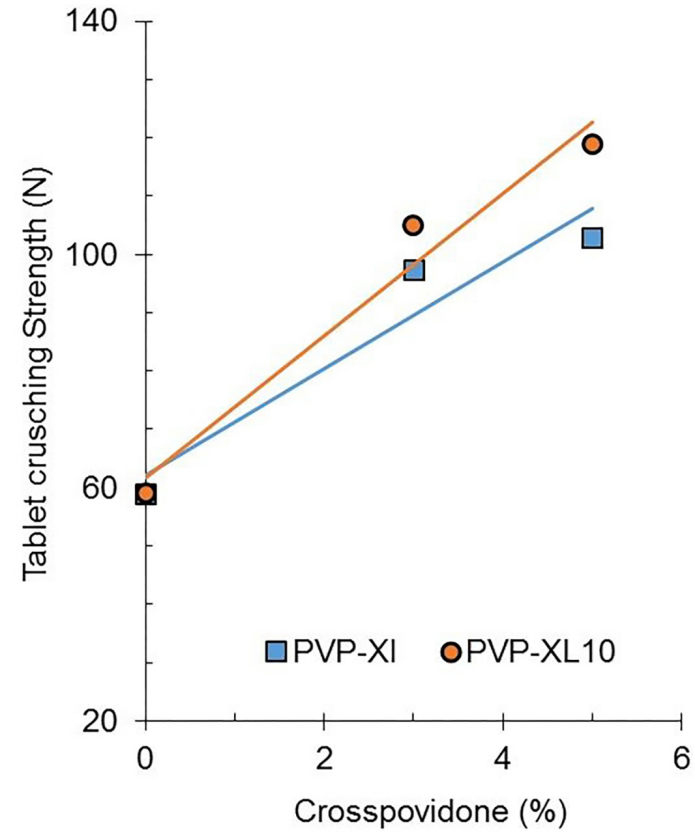

FIGURE 12 - Effect of crospovidones Polyplasdone XL and XL10 on the average compactibility $(\mathrm{Pc}=136 \mathrm{MPa})$ of amoxicillin tablets containing magnesium stearate (1\% and $2 \%)$.

than Polyplasdone XL, although it has also been observed, by oral disintegrating Cetirizine $\mathrm{HCl}$-coated granule tablets, that tablets containing Polyplasdone XL show approximately $12 \%$ higher average compactibility (average of $4.8 \mathrm{kP}$ ) than those containing Polyplasdone XL10 (average of $4.2 \mathrm{kP}$ ). However, this contrasts with the disintegration times of tablets of this drug containing Polyplasdone XL10 (average of $7.3 \mathrm{~s}$ ), which were higher than those of tablets containing Polyplasdone XL (average of $5.7 \mathrm{~s}$ ). These tablets were obtained at compaction forces of $4 \mathrm{kN}, 8 \mathrm{kN}, 10 \mathrm{kN}$ and $12 \mathrm{kN}$ and containing $2 \%, 5 \%$, $10 \%$ and 20\% Polyplasdone (Douroumis et al., 2011).

In conclusion, the compactibility of crospovidones is similar to that of a direct compression agglutinant (Helmcel 200); their average surrogate functionality is Dmax $=353 \mathrm{~N}$, while that of microcrystalline cellulose type 102 (Helmcel 200) is Dmax $=375 \mathrm{~N}$ and that of a direct compression excipient, GalenIQ 720, an agglomerated spherical isomalt for direct compression applications, is Dmax $=134$ N (Samayoa-Sandoval, Villafuerte Robles, 2013). Although crospovidones are lubricant-sensitive (average of 0.23 ), they are less sensitive than other excipients, such as starch $1500(0.53)$ and rice starch (0.31). The ability to improve the compactibility of different tablet matrices (Pharmatose M200, calcium phosphate, amoxicillin +magnesium stearate) is always greater for Polyplasdone XL10 (25-50\%) than for Polyplasdone XL. 


\section{Effect of crospovidones on powder flowability}

\section{Flowability of crospovidones}

Figure 13 depicts the results obtained for the compressibility index of crospovidones and their admixtures with magnesium stearate. As expected, Polyplasdone XL10 exhibits a greater compressibility (32\%) compared to Polyplasdone XL (19\%). This equates to a better powder flow of Polyplasdone XL compared to that of Polyplasdone XL10.

Compared to some other excipients, the compressibility index of microcrystalline cellulose type 102 (Helmcel 200), determined under the same experimental conditions as those employed here, was $21.7 \%$. In the same way, the compressibility of agglomerated isomaltose (GalenIQ 720) was determined to be $13.8 \%$ (Fuentes-Gonzalez, Villafuerte-Robles).

If the compressibility index of crospovidones is referred to Helmcel 200, Polyplasdone XL10 displays a relative powder compressibility of 1.49 , or $49 \%$ greater compressibility than Helmcel 200, while Polyplasdone XL shows a relative powder compressibility of 0.87 or a powder compressibility that is $17 \%$ smaller than that of Helmcel 200. Microcrystalline cellulose type 102, an innovator of Helmcel 200, is considered to be at the limit of the processability of powders in a high-speed tableting machine (Sun, 2010). If that is the case, Polyplasdone XL can be processed without problems, while Polyplasdone XL10 will need the addition of a glidant.

The effect of the widely used lubricant magnesium estearate on the flow properties of Polyplasdone powders is a decrease of fluidity or a small increase in powder compressibility (Figure 13). The trend curves suggest that the soft particles of the lubricant around the polyplasdone crospovidones particles deteriorate the powder fluidity of the binary mixtures to some extent. With regard to the contrasting flowing properties, Polyplasdone XL powder displays greater particle size, and seems to be slightly more sensitive to the effects of magnesium stearate than Polyplasdone XL10, which shows a smaller particle size. This is shown by the slope of regression lines of polyplasdone XL (3.15) and Polyplasdone XL10 (1.95). The greater surface area of Polyplasdone XL10 seems to permit the inclusion of more lubricant particles before they obstruct the powder flow.

It has been observed that magnesium stearate improved the powder flow of spray-dried lactose, until a threshold was reached, at which point the addition of lubricant had no effect (Morin, 2012). However, with lactose 313 , higher amounts of magnesium stearate did not allow the permanence of the improved powder flowability.

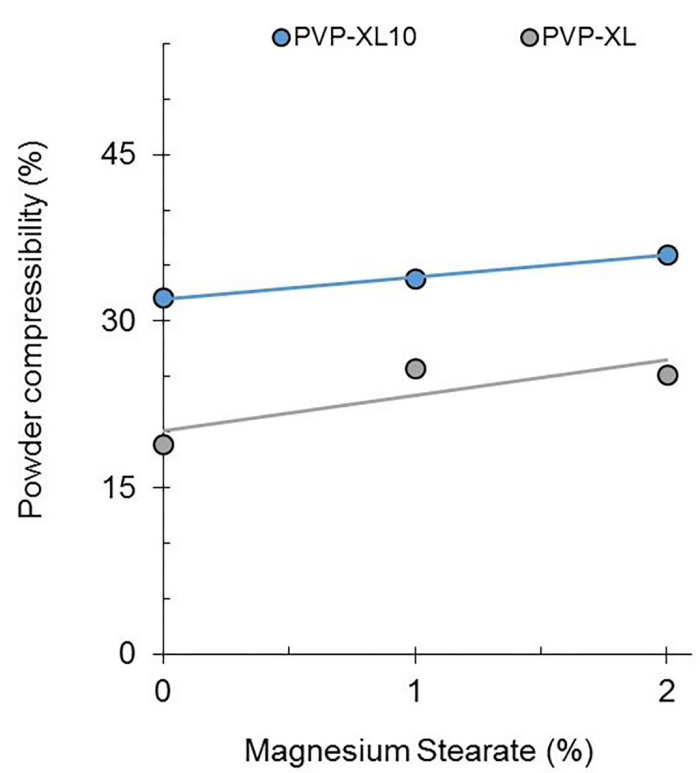

FIGURE 13 - Effect of magnesium stearate on the compressibility of powders of the crospovidones Polyplasdone XL and XL10.

When a greater than optimum amount of magnesium stearate is added, flow properties deteriorate (Hou, Sun, 2007). In the same way, it has been observed that the powder flow of GalenIQ 720 attains a maximum with $0.4 \%$ magnesium stearate (Fuentes-Gonzalez, VillafuerteRobles).

It seems that $1 \%$ and $2 \%$ magnesium stearate are above the optimal proportion of the lubricant to improve the powder flow of crospovidones. Magnesium stearate deteriorates the crospovidone powder flow, at both of the proportions of the lubricant used; this is expressed as an increase in compressibility index.

\section{Effect of crospovidones on the powder fluidity of blends}

Flowability of blends is essentially complex, since flow properties are not only influenced by the physicochemical material factors, but also to a great extent by the particle packing (Nalluri, Kuentz, 2010).

Figure 14 depicts the compressibility index of mixtures of calcium phosphate and crospovidones as a function of the Polyplasdone content. A slight decrease in the compressibility index can be observed, which suggests a slight increase in powder fluidity as the Polyplasdone content increases. The poor powder flow of calcium phosphate $(\mathrm{CI}=47 \%)$ is practically unchanged after the addition of up to $10 \%$ Polyplasdone crospovidones.

Similar results can be observed for Pharmatose M200 mixed with different proportions of crospovidones. Figure 15 depicts the compressibility index of Pharmatose M200 


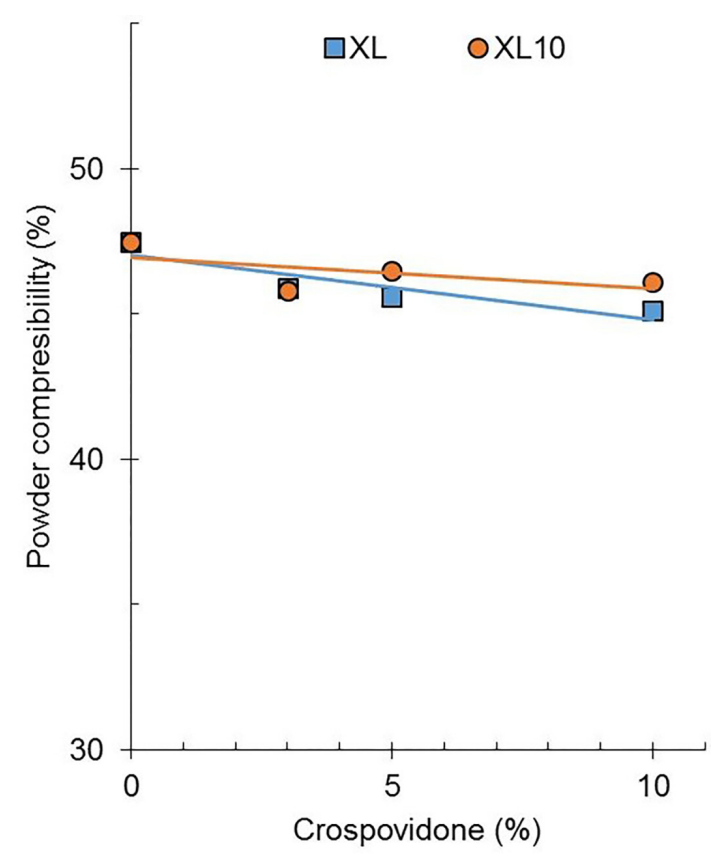

FIGURE 14 - Effect of crospovidones Polyplasdone XL and XL10 on powder compressibility of calcium phosphate.

as a function of the added proportion of crospovidones. The poor powder flow of Pharmatose M200 (CI=42\%) improves after the addition of crospovidones to some extent. This occurs in a slightly higher magnitude for Polyplasdone XL compared to Polyplasdone XL10. This improvement of powder flow agrees with the greater powder flow of Polyplasdone XL compared to that of the type XL10 (Figure 13).

In contrast to the above-mentioned cases of calcium phosphate and Pharmatose M200, the addition of Polyplasdone to amoxicillin containing magnesium stearate as a lubricant increases the compressibility index of the mixtures. This results in a lesser powder flow of amoxicillin containing magnesium stearate after the addition of crospovidones (Figure 16). This circumstance agrees with the increase in powder compressibility observed for crospovidones blended with magnesium stearate. In the first instance, the ability of crospovidones to increase the compressibility index of amoxicillin formulations can be attributed to a similar interaction with magnesium stearate, as mentioned above for crospovidones alone. Moreover, the compressibility index of mixtures containing Polyplasdone XL displays lower values than Polyplasdone XL10. This results in a greater powder flow of mixtures containing Polyplasdone XL compared to those containing Polyplasdone XL10. This is in line with the powder compressibility observed when using mixtures of crospovidones with Pharmatose M200 (Figure 15).

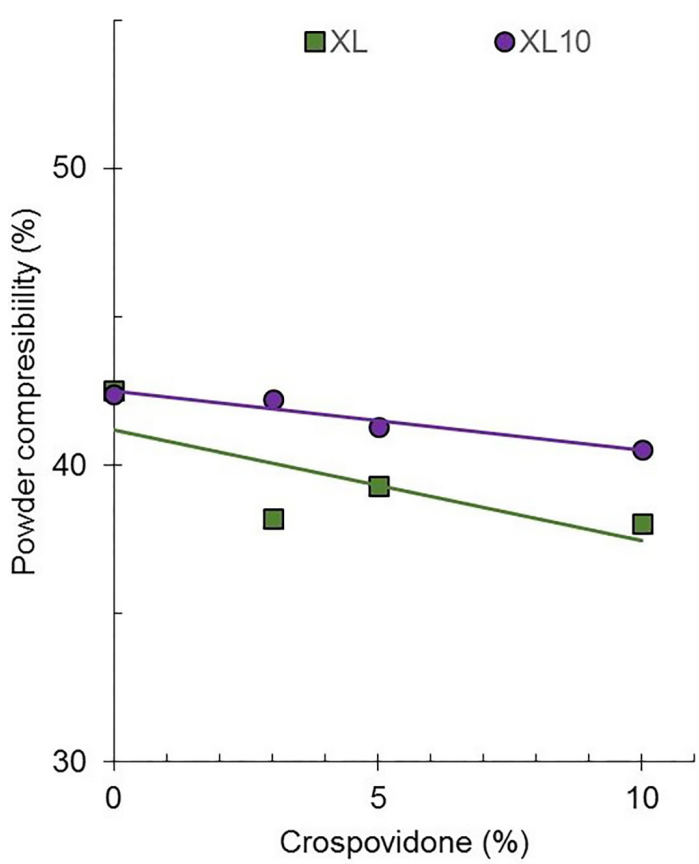

FIGURE 15 - Effect of crospovidones Polyplasdone XL and XL10 on the powder compressibility of Pharmatose M200.

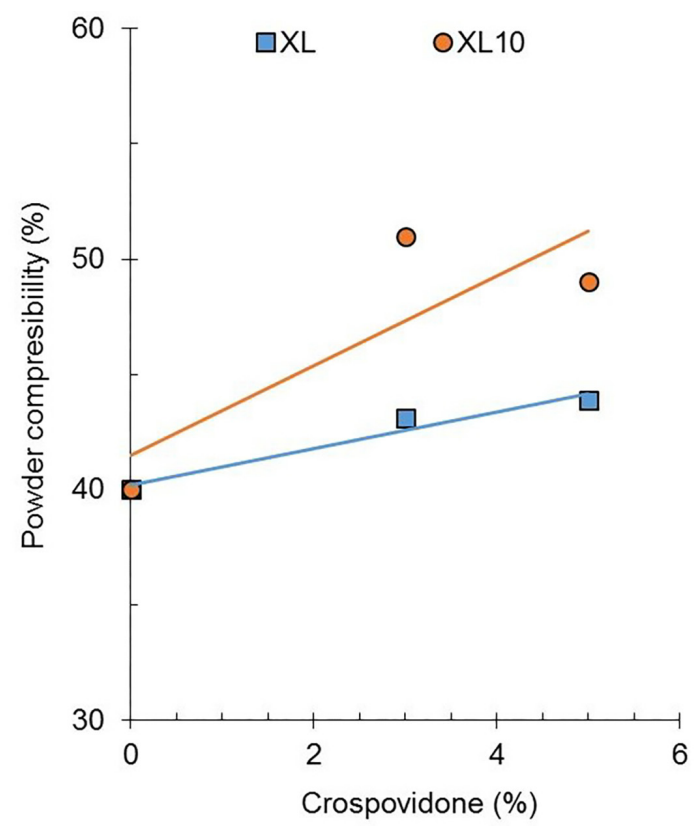

FIGURE 16 - Effect of the crospovidones Polyplasdone XL and XL10 on the powder compressibility of amoxicillin containing $1 \%$ and $2 \%$ magnesium stearate.

The amoxicillin powder flow, determined using a funnel with an opening of $6 \mathrm{~mm}$, shows a reduction of flowability after mixing with magnesium stearate and crospovidones (Figure 17), confirming the previously mentioned results for powder compressibility (Figure 16). 


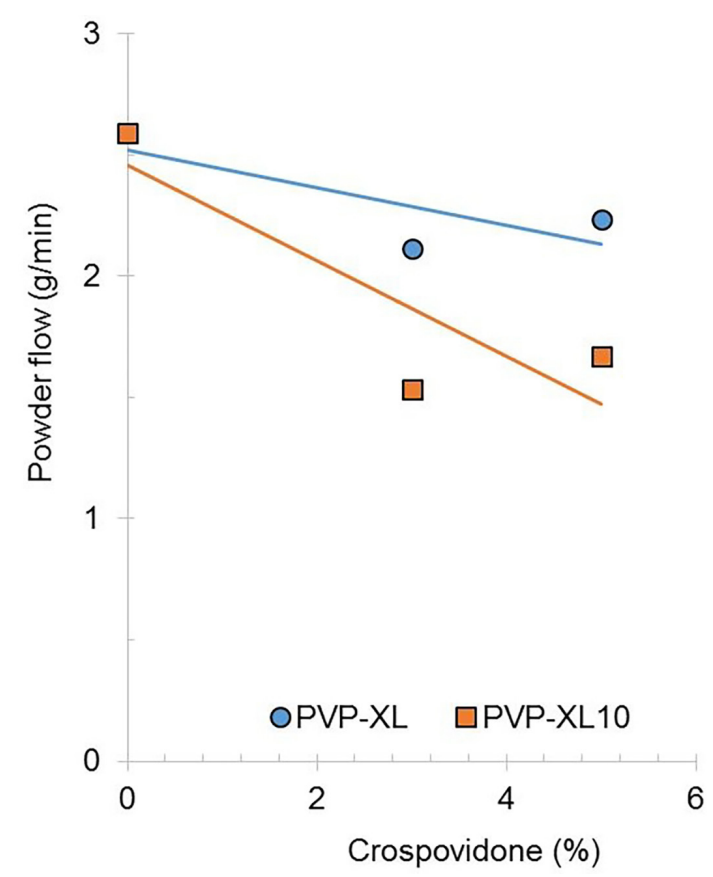

FIGURE 17 - Effect of Polyplasdone XL on the average powder flow, through an opening of $6 \mathrm{~mm}$, for amoxicillin containing $1 \%$ and $2 \%$ magnesium stearate.

Also, in Figure 17, a higher flowability of mixtures containing Polyplasdone XL compared to those containing Polyplasdone XL10 can be observed, confirming the previously mentioned results of powder compressibility (Figure 16).

Amoxicillin powder flow $(2.59 \mathrm{~g} / \mathrm{min})$ decreases in flowability by about $31 \%$ after the addition of Polyplasdone XL, up to $1.78 \mathrm{~g} / \mathrm{min}$, while a reduction in flowability of about $43 \%$, up to $1.47 \mathrm{~g} / \mathrm{min}$, is seen after the addition of Polyplasdone XL10.

To conclude, crospovidone proportions up to $10 \%$ have little effect on the flow properties of some other excipients and drugs, slightly increasing the powder flow of some excipients. However, the addition of magnesium stearate to crospovidones reduces their powder flow as excipients alone as well as in formulations containing crospovidones. Contrasting the flow functionality of crospovidones, Polyplasdone XL displays a mostly greater powder flow (average of above mentioned formulations, $\mathrm{CI}=37.3 \%$ ) than Polyplasdone XL10 (average of $\mathrm{CI}=44.8 \%$ ). Polyplasdone XL appears to be more sensitive to magnesium stearate, reducing its flowability to a greater extent (increase of about $37 \%$ in compressibility index) than Polyplasdone XL10 (increase of about $13 \%$ in compressibility index). This behavior is attributed to the smaller particle size of Polyplasdone XL10, displaying greater interparticle friction and a greater surface area to distribute the added magnesium stearate, diminishing its negative effect on its flowability.

Table I summarizes all of the parameters studied. The outcomes are presented as averages of the results obtained by the different types of formulations. The influence of crospovidone type can be compared individually for each type of formulation, containing magnesium stearate, Pharmatose M200, calcium phosphate or amoxicillin.

\section{CONCLUSION}

The functionality of crospovidones Polyplasdone XL and XL10 has been found to be different. The current results and those found in the literature are coincident, showing a similar qualitative functionality, but different quantitative functionality, of the Polyplasdones XL and XL10. Generally, Polyplasdone XL tablets display shorter disintegration times than Polyplasdone XL10 by about a half. The disintegration times are in line with a $25-50 \%$ higher ability of Polyplasdone XL10 to improve the compactibility of other materials compared to Polyplasdone XL. The higher compactibility of Polyplasdone XL10 delays the disintegration times. Nevertheless, both excipients are highly functional as disintegrants and dry agglutinants. Their agglutinant functionality is similar to the known functionality of microcrystalline cellulose type 102. Also similar to microcrystalline cellulose is the sensitivity of crospovidones to magnesium

TABLE I - Crospovidone functionality considering the disintegration time (DT), tablet crushing strength (TCS) and compressibility index (CI), expressed as averages of different types of formulations

\begin{tabular}{lcccccccc}
\hline \multirow{2}{*}{$\begin{array}{l}\text { Functional } \\
\text { Property }\end{array}$} & \multicolumn{9}{c}{ Polyplasdone } \\
\cline { 2 - 9 } & \multicolumn{1}{c}{ XL 10 } & XL & XL 10 & XL & XL 10 & XL & XL 10 & XL \\
\cline { 2 - 9 } & \multicolumn{2}{c}{+ +MS } & \multicolumn{2}{c}{+ +Pharm } & & + CPh & & +Amoxi \\
\hline DT (s) & 150.7 & 60.3 & 19.5 & 8.9 & 2.6 & 4.7 & 49.6 & 17.7 \\
TCS (N) & 245.5 & 227.5 & 106.0 & 90.3 & 90.7 & 82.7 & 112.0 & 100.0 \\
CI (\%) & 34.9 & 25.5 & 41.3 & 38.5 & 46.1 & 45.5 & 50.0 & 43.4 \\
\hline
\end{tabular}

MS: magnesium srearate; Pharm: Pharmatose M200; CPh: calcium phosphate; Amoxi: amoxicilin. 
stearate, although it is less than that shown by other superdisintegrants like Starch 1500. The flow properties of Polyplasdone crospovidones are also different, although their impact on other pharmaceutical materials is not of great consequence in the usual proportions in which they are used. Nevertheless, Polyplasdone XL10 displays about $20 \%$ greater compressibility indexes than Polyplasdone XL. This means a good flowing Polyplasdone XL, while Polyplasdone XL10 will need the addition of glidants. These properties of Polyplasdones are related to the smaller particle size of Polyplasdone XL10 compared to Polyplasdone XL.

\section{REFERENCES}

AHMAD, M. Z.; AKHTER, S.; ANWAR, M.; RAHMAN, M.; SIDDIQUI, M. A.; AHMAD, F. J. Compactibility and compressibility studies of Assam Bora rice starch. Powder Technol., v.224, p.281-286, 2012.

BARRIOS-VAZQUEZ, S. C.; VILLAFUERTE-ROBLES, L. Functionality of GalenIQ 721 as excipient for direct compression tablets. J. App. Pharm. Sci., v.3, p.8-19, 2013.

BÜHLER, V. Polyvinylpyrrolidone excipients for pharmaceuticals, Chapter 3, Insoluble polyvinylpyrrolidone (crospovidone). Springer, Berlin, Heidelberg. 2005. ISBN: 978-3-540-23412-8 (Print) 978-3-540-27090-4 (Online) Review citation in accordance with ABNT norms.

CALCIUMAND WATER: reaction mechanisms, environmental impact and health effects. Lenntech BV. Available at: $<$ http://www.lenntech.com/periodic/water/calcium/ calcium-and-water.htm $>$. Accessed on 25 June, 2013.

CASTILLO, S.; VILLAFUERTE, L. Compactibility of binary mixtures of pharmaceutical powders. Eur. J. Pharm. Biopharm., v.41, p.309-314, 1995a.

CASTILlo, S.; VILlAFUERTE, L. Compactibility of ternary mixtures of pharmaceutical powders. Pharm. Acta Helv.,v.70, p.329-337, 1995b.

CHAULANG, G. M.; PATIL, K. S.; GHODKE, D. S.; YEOLE, P. G.; BHOSALE, A. V.; HARDIKAR, S. J. Effect of some physical parameters and crospovidone on directly compressed frusemide tablets. Asian J. Pharm., v.2, p.235240, 2008.
CHEN, C.; YAW, L.; SHU, C.; SHU, Y. Investigation of the dissolution difference between acidic and neutral media of acetaminophen tablets containing a super disintegrant and a soluble excipient. Chem. Pharm. Bull., v.45, p.1048-51, 1997.

DÍAZ RAMÍREZ, C. C.; VILLAFUERTE ROBLES, L. Surrogate functionality of celluloses as tablet excipients. Drug Dev. Ind. Pharm., v.36, p.1422-1435, 2010.

DOUROUMIS, D. D.; GRYCZKE, A.; SCHMINKE, S. Development and Evaluation of Cetirizine $\mathrm{HCl}$ TasteMasked Oral Disintegrating Tablets. AAPS PharmSciTech, v.12, 2011.

FICHTNER, F.; MAHLIN, D.; WELCH, K.; GAISFORD, S.; ALDERBORN, G. Effect of Surface Energy on powder compactibility. Pharm. Res., v.25, p.2750-2760, 2008.

FUENTES-GONZALES, K.I.; VILLAFUERTE-ROBLES, L. Powder fluidity as a functionality parameter of the excipient GalenIQ 720. Int. J. Pharm. Pharm. Sci., v.6, p.66-74, 2014.

FUJII, M.; OKADA, H.; SHIBATA, Y.; TERAMACHI, H.; KONDOH, M.; WATANABE, Y. Preparation, characterization, and tableting of a solid dispersion of indomethacin with crospovidone. Int. J. Pharm., v.293, p.145-153, 2005.

GORDON, M. S; CHOWHAN, Z. T. Effect of tablet solubility and hygroscopicity on disintegrant efficiency in direct compression tablets in terms of dissolution. J. Pharm. Sci., v.76, p.907-909, 1987.

GOYANI, S. M.; SHAH, P.; BHAVIN, V.; SHAH, D. R. Formulation and evaluation of orally disintegtrating tablets of meclizine hydrochloride. Int. Res. J. Pharm., v.3, p.196199, 2012.

HOU, H.; SUN, C. Effect of magnesium stearate on powder flow properties. AAPS Annual Meeting and Exposition. Published Meeting Abstracts. AAPS2007-001075, poster W4352.

ILIĆA, I.; KÁSA, P.; DREUA, R.; PINTYE-HÓDI, K.; SRČIČA, S. A modification of the Pr value equation for measuring the compactibility of pharmaceutical materials. Chem. Eng. Proc: Process Intensification, v.49, p.881-884, 2010. 
JAIN, S. P.; MEHTA, D. C.; SHAH, S. P.; SINGH, P. P.; AMIN, P. D. Melt-in-mouth pellets of fexofenadine hydrochloride using crospovidone as an extrusion-spheronisation aid. AAPS PharmSciTech., v.11, p.917-923, June, 2010. Available at: $<$ http://www.ncbi.nlm.nih.gov/pmc/articles/ PMC2902318/>. Accessed on 21 June, 2013.

KASLIWAL, N. J.; SINGH, N. Development, characterization and performance evaluation of oro-dispersible tablet containing aceclofenac hydroxypropyl-b-cyclodextrin binary system. J. Incl. Phenom. Macrocycl. Chem., v.71, p.215-224, 2011.

KIBBE, A. H. (Ed.). Handbook of pharmaceutical excipients, 3 ed., London: Pharmaceutical Press, 2000. 641p.

KUMAR, G. P.; NIRMALA, R. Fundamental aspects of superdisintegrants: a concise review. J. Global Pharma Tech., v.4, p.1-12, 2012.

LACTOSE, MONOHYDRATE (10039-26-6). Chemical Book. Available at: $<$ http://www.chemicalbook.com/ProductCh emicalPropertiesCB8685418_EN.htm>. Accessed on 25 June, 2013.

LÓPEZ-SOLIS, J.; VILLAFUERTE-ROBLES, L. Effect of disintegrants with different hygroscopicity on dissolution of norfloxacin: Pharmatose DCL 11 tablets. Int. J. Pharm., v.216, p.127-135, 2001.

MACHADO, J. B.; COUTINHO, J. A.; MACEDO, E. A. Solidliquid equilibrium of $\alpha$-lactose in ethanol/water. Fluid Phase Equilibr., v.173, p.121-34, 2001

MEHTA, S.; DE BEERB, T.; REMON, J. P.; VERVAET, C. H. Effect of disintegrants on the properties of multi-particulate tablets comprising starch pellets and excipient granules. Int. J. Pharm., v.422, p.310-317, 2012.

MIINEA, L.; FARINA, J.; KALLAM, M.; DEORKA, N. ANew World of Excipients for Oral Solid Dosage Formulation. Monday, February 2, 2009. Available at: <http://www. pharmpro.com/Articles/2009/03/A-New-World-ofExcipients-for-Oral-Solid-Dosage-Formulation/>. Accessed on: December 09, 2011.

MOHAMED, M .B.; TALARI, M. K.; TRIPATHY, M.; MAJEED, A. B. S. Pharmaceutical applications of crospovidone: a review. Int. J. Drug Form. Res., v.3, p.1328, 2012.
MORIN, G. J. 2012. The effects of lubrication on pharmaceutical granules. Thesis of Master of Engineering Science. School of Graduate and Postdoctoral Studies. The University of Western Ontario London, Ontario, Canada.

MRUDULA H. B.; DERLE, D. V. Brand to brand variation in the disintegrant functionality of polacrilin potassium, NF. J. Excip. Food Chem., v.2, p.53-63, 2011.

NALLURI, V. R.; KUENTZ, M. Flowability characterization of drug-excipient blends using a novel powder avalanching method. Eur. J. Pharm. Biopharm., v.74, p.388-396, 2010.

NORDSTRÖM, J.; KLEVAN, I.; ALDERBORN, G. A protocol for the classification of powder compression characteristics. Eur. J. Pharm. Biopharm, v.80, p.209-216, 2012.

PARIKH, D. M. An overview of the properties of pharmaceutical powders and their effects on processability. Am. Pharm. Rev. Tuesday, April 30, 2013. Available at: <http:// www.americanpharmaceuticalreview.com/FeaturedArticles/135986-An-Overview-of-the-Propertiesof-Pharmaceutical-Powders-and-their-Effects-onProcessibi\%E2\%80\%A6>. Accessed on 24 June, 2013.

P O L Y P L A S D O N E C R O S P O V I D O N E SUPERDISINTEGRANTS. Product overview. Available at: <http://www.ashland.com/Ashland/Static/Documents/ ASI/PC_11319_Polyplasdone_Overview.pdf $>$. Accessed on 26 August, 2013.

QUADIR, A.; KOLTER, K. A comparative study of current disintegrants. Pharm Tech., Oct 1, 2006. Available at: <http://www.pharmtech.com/pharmtech/article/ articleDetail.jsp?id=378399>. Accessed on: 21 June, 2013.

RAMOS, F.; BOISON, J.; FRIEDLANDER, L. G. Amoxicillin, First draft prepared by Fernando Ramos, Coimbra, Portugal, Joe Boison, Saskatoon, Canada and Lynn G. Friedlander, Rockville, MD, USA. Available at: <ftp://ftp.fao.org/ag/ agn/jecfa/vetdrug/12-2012-amoxicillin.pdf $>$. Accessed on: 25 June, 2013. - include citation on text

RIOS, M. Developments in Powder Flow Testing. A harmonized USP chapter and sophisticated measuring systems are small steps toward understanding powder flowability. Pharm Tech., February 2, 2006. Available at: <http:// www.pharmtech.com/pharmtech/article/articleDetail. jsp?id=301457>. Accessed on March 04, 2013. 
ROCHE JOHNSON, J.; WANG, L. H.; GORDON, M. S.; CHOWHAN, Z. T. Effect of formulation solubility and hygroscopicity on disintegrant efficiency in tablets prepared by wet granulation, in terms of dissolution. J. Pharm. Sci., v.80, p.469-471, 1991.

SALEM, A. S.; PILLAI, G. K.; BADWAN, A. A. Effect of Crospovidone on the Physical Properties of Acetaminophen Tablets. Drug Dev. Ind. Pharm., v.21, p.1807-1814, 1995.

SAMAYOA-SANDOVAL, L.; VILLAFUERTE-ROBLES, L. Compactibility as a functionality parameter of the excipient GalenIQ 720. Rev. Mex. C. Farm., v.44, p.34-45, 2013.

SRINARONG, P.; FABER, J. H.; VISSER, M. R.; HINRICHS, W. L. J.; FRIJLINK, H. W. Strongly enhanced dissolution rate of fenofibrate solid dispersion tablets by incorporation of superdisintegrants. Eur. J. Pharm. Biopharm., v.73, p.154-161, 2009.
SUN, C. C. Setting the bar for powder flow properties in successful high speed tableting. Powder Technol., v.201, p.106-108, 2010.

VILLAFUERTE, L. Propiedades reológicas de los polvos farmacéuticos: un nuevo equipo. Rev. Mex. C. Farm., v.32, p.11-15, 2001.

ZHAO, N.; AUGSBURGER, L. Functionality comparison of 3 classes of superdisintegrants in promoting aspirin tablet disintegration and dissolution. AAPS PharmSciTech., v.6, p.E634-E640, 2005.

Received for publication on $18^{\text {th }}$ September 2013 Accepted for publication on $28^{\text {th }}$ April 2014 
